\title{
Article \\ A Retrospective Cohort Study on Human Cystic Echinococcosis in Khyber Pakhtunkhwa Province (Pakistan) Based on 16 Years of Hospital Discharge Records
}

\author{
Huma Khan ${ }^{1}$, Adriano Casulli ${ }^{2,3, *(D)}$, Majid Fasihi Harandi ${ }^{4}$, Muhammad Sohail Afzal ${ }^{5}$, \\ Muhammad Arif Nadeem Saqib ${ }^{6}$ and Haroon Ahmed ${ }^{1, *}$
}

Citation: Khan, H.; Casulli, A.; Harandi, M.F.; Afzal, M.S.; Saqib, M.A.N.; Ahmed, H. A Retrospective Cohort Study on Human Cystic Echinococcosis in Khyber Pakhtunkhwa Province (Pakistan) Based on 16 Years of Hospital Discharge Records. Pathogens 2022, 11, 194. https://doi.org/10.3390/ pathogens11020194

Academic Editor: Lawrence S. Young

Received: 27 December 2021 Accepted: 28 January 2022 Published: 1 February 2022 Publisher's Note: MDPI stays neutral with regard to jurisdictional claims in published maps and institutional affiliations.

Copyright: (C) 2022 by the authors. Licensee MDPI, Basel, Switzerland. This article is an open access article distributed under the terms and conditions of the Creative Commons Attribution (CC BY) license (https:// creativecommons.org/licenses/by/ $4.0 /)$.
1 Department of Biosciences, COMSATS University Islamabad (CUI), Islamabad 4550, Pakistan; hrk267@hotmail.com

2 WHO Collaborating Centre for the Epidemiology, Detection and Control of Cystic and Alveolar Echinococcosis, Department of Infectious Diseases, Istituto Superiore di Sanità, 00161 Rome, Italy

3 European Union Reference Laboratory for Parasites, Department of Infectious Diseases, Istituto Superiore di Sanità, 00161 Rome, Italy

4 Research Center for Hydatid Disease in Iran, Department of Medical Parasitology, Kerman University of Medical Sciences, Kerman 761, Iran; fasihi@kmu.ac.ir

5 Department of Life Sciences, School of Science, University of Management and Technology (UMT), Lahore 54782, Pakistan; sohail.afzal@umt.edu.pk

6 Department of Medical Laboratory Technology, National Skills University Islamabad, Islamabad 4550, Pakistan; arif.nadeem@nsu.edu.pk

* Correspondence: adriano.casulli@iss.it (A.C.); haroonahmed@comsats.edu.pk (H.A.)

\begin{abstract}
Human cystic echinococcosis (CE) is a worldwide-distributed parasitic zoonotic disease, which represents a threat for both human and animals. The current study aimed at estimating the prevalence of human CE in Khyber Pakhtunkhwa (KPK) province of Pakistan. Clinical records from four major hospitals in this region were reviewed for CE human cases during the period of 2006-2021. Out of $251(0.00071 \%)$ CE patients identified during the considered period, 142 (56.6\%) were females, and $109(43.4 \%)$ were males. The highest number of CE cases was recorded in the 21-30 (27.9\%) age group, followed by 31-40 (23.1\%) and 41-50 (16.3\%). Most of the CE patients in KPK province were members of the Afghani ethnic group (17.1\%); secondarily, they were Pakistani (6.4\%), while for $76.5 \%$ ethnicity data were not available. The liver (41\%) and the lungs $(4.8 \%)$ were the most infected organs identified among CE patients in KPK province. The present study identified CE as a significant public health problem in KPK province, and the current findings demonstrated a constant endemicity of CE during the last 15 years. Further filed studies on the active search of CE carriers by means of ultrasound population-based surveys are needed to fill knowledge gaps on clinical and molecular epidemiology of human CE in Pakistan.
\end{abstract}

Keywords: human cystic echinococcosis; clinical epidemiology; Khyber Pakhtunkhwa province; Pakistan

\section{Introduction}

Cystic (CE) and alveolar (AE) echinococcosis are zoonotic parasitic diseases caused by the larval stages of tapeworms Echinococcus granulosus sensu lato (s.l.) and Echinococcus multilocularis, respectively. These zoonotic diseases are included in the World Health Organization (WHO) portfolio, which is prioritizing their control [1]. According to 2007 estimates, 1.2 million people are affected globally with loss of 3.6 million Disability-Adjusted Life Years (DALYs) due to human infection [2], and over USD 3 billion economic losses are reported annually [3,4]. In Pakistan, a total cost of USD 4,068,666 (95\% CI: USD 3,097,684-5,295,702) was estimated for the year 2017, with USD 3,951,853 (95\% CI: USD 2,981,400-5,177,610) attributable to direct diagnosis and treatment-related costs and USD 117,137 (95\% CI: USD 91,841-146,979) attributable to wage losses during the treatment period [5]. The life 
cycle of E. granulosus s.l. involves two mammal animal hosts. Canids such as dogs act as definitive hosts, harbouring the adult worm stage in the intestine. Ungulates such as livestock act as intermediate hosts, harbouring the asexual metacestode stage in the abdominal cavity and can be infected through fecal oral route with eggs shed with dog feces [6]. Humans are dead-end hosts, which acquire infection through Echinococcus viable eggs ingestion by contaminated food and water, a hand-to-mouth pathway, or contact with dogs [7]. The ingested eggs hatch in the small intestine and release six-hooked oncospheres, which penetrate the intestinal wall and are transported to various organs or tissues through blood, but echinococcal cysts most commonly develop in the liver and the lungs. The preliminary stage of disease is always asymptomatic or paucisymptomatic, unless complications occur, depending on the size, number, localization, and stage of the cyst. In symptomatic individuals, the chance of cyst rupture is high, and spillage of cyst content (infective protoscoleces) may cause secondary infection [8].

Echinococcus granulosus s.l. is a complex of cryptic species that can be identified by molecular approaches. E. granulosus s.l. is currently divided in the following species: Echinococcus granulosus sensu stricto (s.s.) (genotypes G1 and G3), Echinococcus equinus (G4), Echinococcus ortleppi (G5), Echinococcus canadensis cluster (G6/7, G8, and G10), and Echinococcus felidis (lion strain). The life cycle of the parasites and their pathogenicity, specificity, transmission dynamics, and epidemiology may differ between genotypes/species. E. granulosus s.s. $(\mathrm{G} 1, \mathrm{G} 3)$ is considered the most important species causing human cystic echinococcosis (CE) globally [9]. CE is worldwide distributed, but the regions with high endemicity of human CE infection are the Mediterranean region, South America, Asia, and the Middle East including Pakistan and Afghanistan. There is paucity of research on CE in endemic regions of Pakistan [10-12]. The land use in Pakistan is pastoral, agropastoral, and agricultural, where human populations live in close association with livestock. Animal husbandry plays a significant role in the economic sustainability and gross domestic product (GDP) of the country. In Pakistan, about $47 \%$ of the population is involved in the agricultural sector [13]. Livestock contributes $60 \%$ in agriculture with a $12.8 \%$ growth in livestock and poultry products [13]. Risk factors for CE infection include free-roaming dogs, home slaughtering, and being a pet owner (dogs) $[8,14]$. Furthermore, CE transmission may be influenced by climatic and environmental factors affecting the eggs' survival [15].

Studies assessing CE epidemiology have confirmed this zoonotic disease as a major public health problem in central Asia [16]. In fact, 270 million people (58\% of the population) are at risk of cystic and alveolar echinococcosis in Central Asia, including Kazakhstan, Tajikistan, Kyrgyzstan, Uzbekistan, Afghanistan, Pakistan, Western China, and Iran [17]. Countries included in the Iranian plateau (Pakistan, Turkey, and Iran) are highly endemic regions. All three neighbouring countries (Afghanistan, China, and India) share socioeconomic and cultural relations with Pakistan, but none of these countries have control programmes for echinococcosis because of the lack of information regarding this zoonotic disease [18]. The surgical incidence rate of human CE in Iran has been estimated at $1.27 / 100,000$ population, with an average of 1295 surgical operations reported annually for the years 2000-2009, and the number of asymptomatic human CE cases in this country was estimated at 635,232 [19]. Based on the Ministry of Health's official report in Turkey, 52,000 patients underwent CE surgery between 1990 and 2005. The annual CE incidence rate in Turkey ranged from $0.8 / 100,000$ to $2 / 100,000$ [20], with a significant raise in the CE incidence rate until 6.4/100,000 in some regions of the country [21]. A more recent cross-sectional ultrasound population-based study estimated around 106,000 individuals who might be infected by CE in Turkey [22]. The human CE prevalence rate in highly endemic China was estimated at 10.57/10,000 with 47,278 cases of both CE and AE that were recorded in 2018 in 370 different endemic states [23].

In the past decades, few epidemiological studies on echinococcosis, like for other neglected tropical diseases, have been conducted in Pakistan, with human CE cases reported from the provinces of Punjab [11,12,24], Sindh [25], and Khyber Pakhtunkhwa [26]. In addition, a recent review highlighted 1702 human CE cases in Pakistan reported between 
2000 and 2020 [12]. Khyber Pakhtunkhwa (KPK) is one of most populated provinces of Pakistan, and it is bordering with Afghanistan. The burden of human CE, envisaged for the implementation of control programs, is poorly known in KPK, where the majority of people are working in the agriculture sector and in animal husbandry. In the recent years, the majority of the CE cases have been reported in Afghan people migrating to several localities, including Khyber Pakhtunkhwa (KPK) province [14]. Therefore, the current study was designed to assess the demographic and epidemiological characteristics of human CE cases based on hospital records during a 16-year period in KPK province (Pakistan).

\section{Results}

In the current study, a total of 251 patients with CE were diagnosed and surgically operated in four major hospitals (Rehman Medical Institute (RMI), Peshawar Medical College (PMC), Institute of Kidney Disease (IKD), and Khyber Teaching Hospital (KTH)) during the 2006-2021 period with 16,56 cases per year (Figure 1).

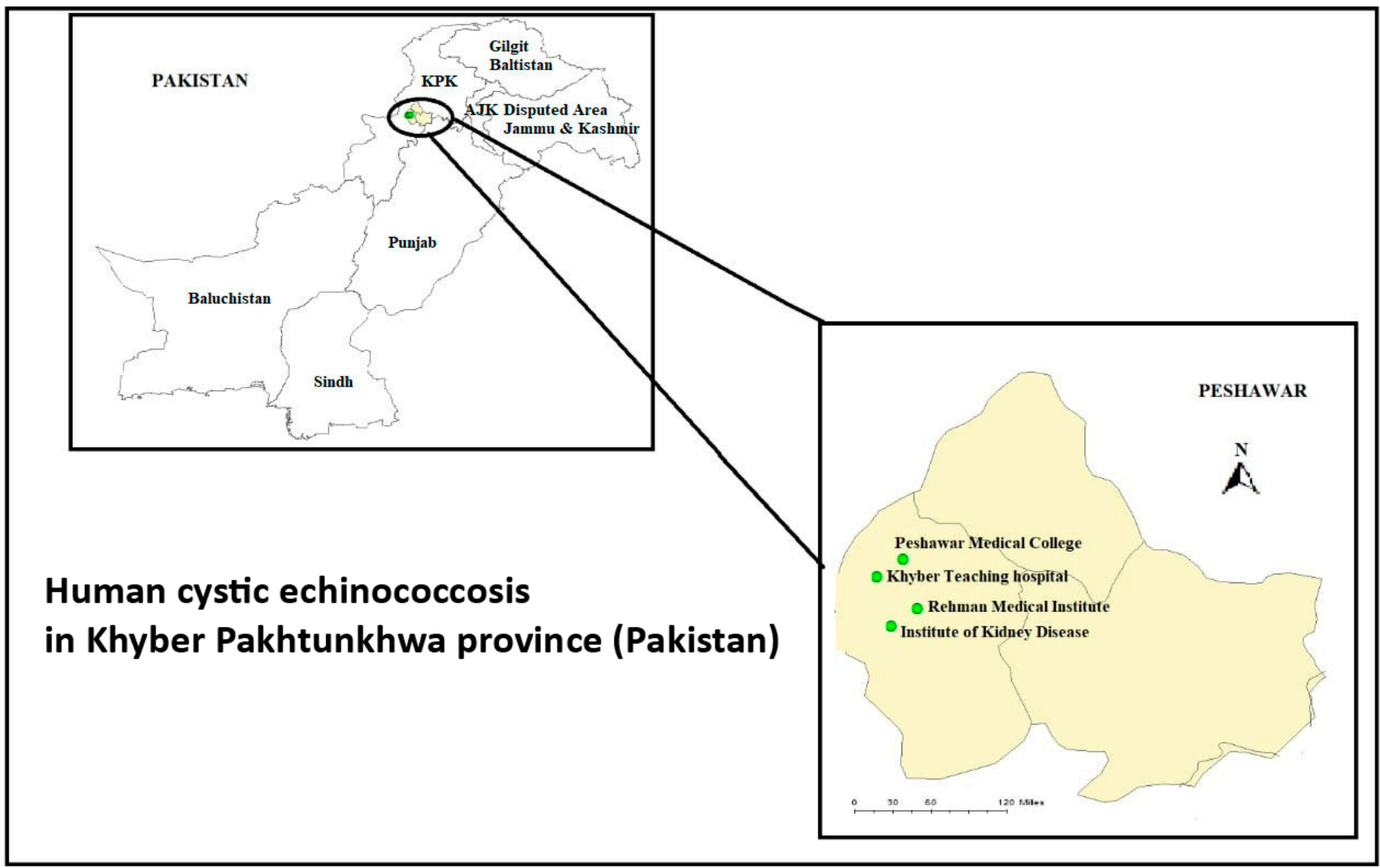

Figure 1. Map of Khyber Pakhtunkhwa province (Pakistan) showing the sites where the study was conducted: (1) Peshawar Medical College, (2) Khyber Teaching Hospital, (3) Rehman Medical Institute, and (4) Institute of Kidney Disease.

The highest number of histopathologically confirmed CE cases were reported in RMI $(60.95 \% ; n=153)$ followed by PMC $(32.66 \% ; n=82)$, while lower number of cases were in KTH $(3.98 \% ; n=10)$ and IKD $(2.40 \% ; n=6)$. The highest annual CE cases were recorded in $2012(16.73 \%)$ followed by 2019 with $11.95 \%$, while the lowest frequencies were recorded in 2006 and $2021(0.40 \%)$ (Figure 2). The current findings were based on clinical records of operated CE patients. 


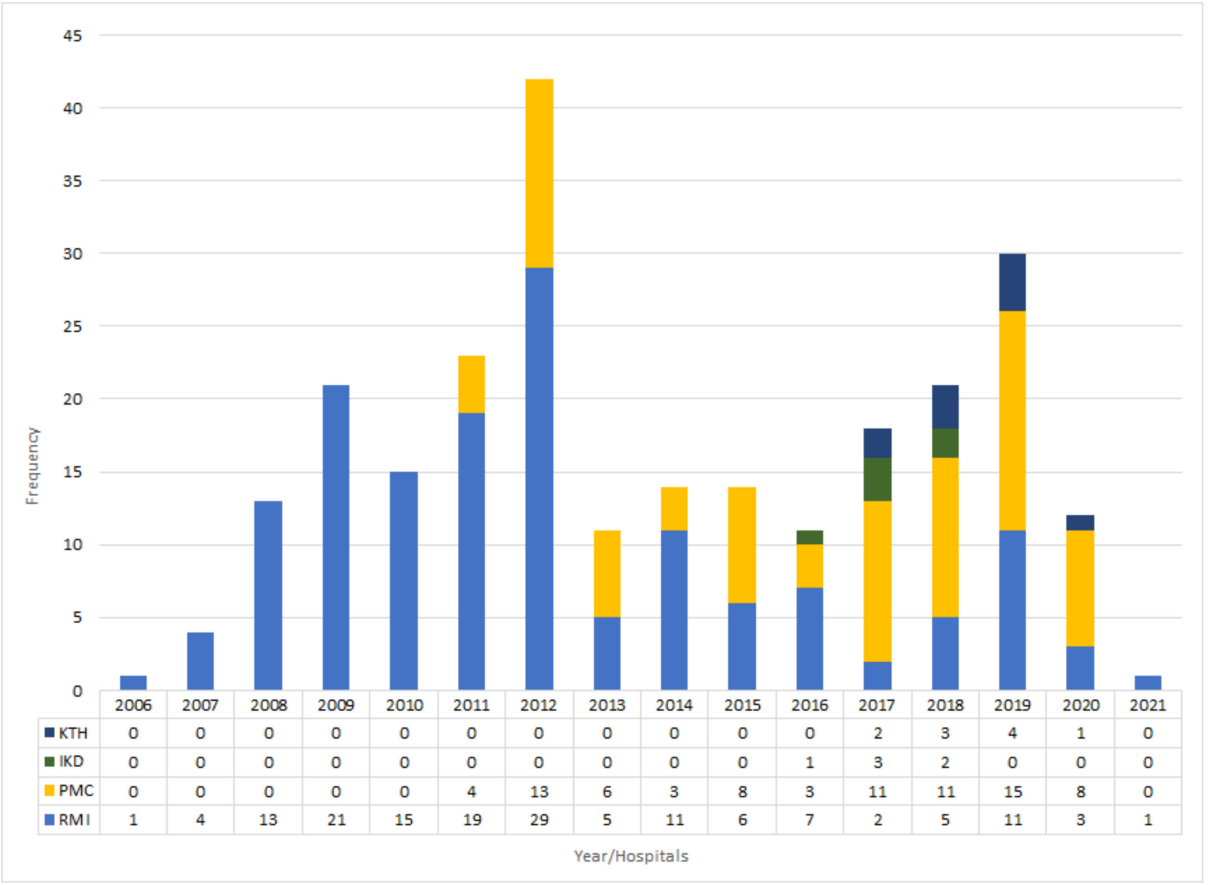

Figure 2. Frequency of cystic echinococcosis in four major hospitals of Khyber Pakhtunkhwa province (Pakistan) during the years of 2006-2021.

Surgery was done after echinococcal cyst identification by diagnostic imaging techniques like, ultrasound (US), computed tomography (CT), or magnetic resonance imaging (MRI). All patients received antihelminthic treatment with albendazole as an adjuvant to surgical procedures. In Pakistan, albendazole is commonly prescribed to all CE patients. The highest number of positive cases $(27.9 \%)$ were observed in the $21-30$ age group followed by the $31-40(23.1 \%)$ and $41-50(16.3 \%)$ age groups, while the lowest cases were recorded in the 71-80 $(0.39 \%)$ age group. Based on the clinical data, the number of CE cases was observed more in females $(56.6 \%)$ than males $(43.4 \%)$. For both genders, most cases were recorded in the $21-30$ and $31-40$ age groups (Figure 3).

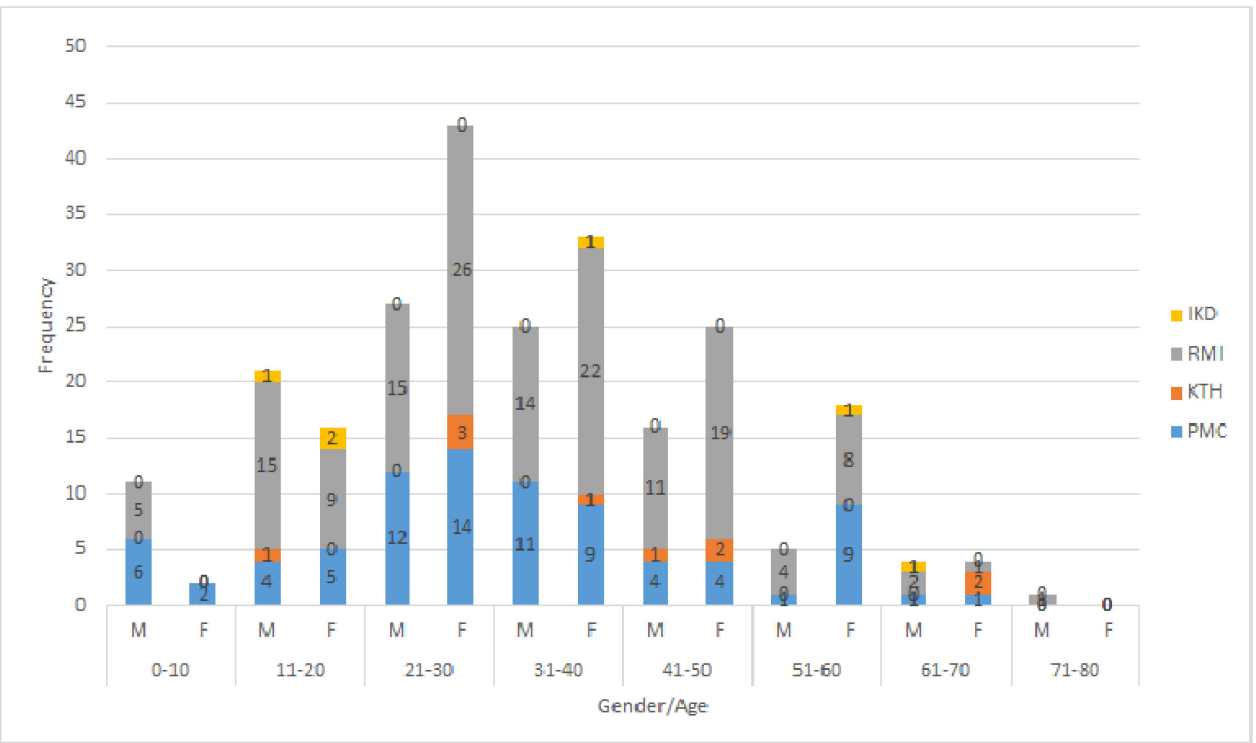

Figure 3. Age- and gender-wise frequency of cystic echinococcosis cases from four major hospitals of Khyber Pakhtunkhwa during the years 2006-2021. M, male; F, female). 
The cyst localization from four major health complexes of KPK is summarized in Table 1. The CE cases identified in the present study belonged to two ethnic groups. Among the recorded cases, 43 (17.13\%) were Afghani, and 16 (6.37\%) were Pakistani, while for $192(76.49 \%)$, data were not available.

Table 1. Ethnicity and anatomical localization of echinococcal cysts of human origin from Khyber Pakhtunkhwa province, Pakistan.

\begin{tabular}{ccc}
\hline Ethnicity & Number of Cases & Percentages \\
\hline Afghani & 43 & $17.13 \%$ \\
Pakistani & 16 & $6.37 \%$ \\
Not available & 192 & $76.49 \%$ \\
\hline Total & 251 & \\
\hline Body organ & & \\
\hline Liver & 103 & $41.0 \%$ \\
Liver and Omentum & 1 & $0.40 \%$ \\
Liver/spleen/pelvis & 2 & $0.80 \%$ \\
Lung & 12 & $4.78 \%$ \\
Lung and liver & 3 & $1.19 \%$ \\
Spleen & 9 & $3.58 \%$ \\
Abdomen & 7 & $2.78 \%$ \\
Gall bladder & 3 & $1.19 \%$ \\
Neck & 1 & $0.40 \%$ \\
Omentum & 3 & $1.19 \%$ \\
Ovary & 1 & $0.40 \%$ \\
Right flank & 3 & $1.19 \%$ \\
Right paraspinal cyst & 1 & $0.40 \%$ \\
Shoulder & 1 & $0.40 \%$ \\
Spleen and liver & 2 & $0.80 \%$ \\
Thyroid & 2 & $0.80 \%$ \\
Vertebrae & 2 & $0.80 \%$ \\
Others & 23 & $9.16 \%$ \\
Site not mentioned & 72 & $28.60 \%$ \\
\hline Total & 251 & \\
\hline
\end{tabular}

The most commonly affected organ was the liver (41\%) followed by the lungs (4.78\%) and the spleen (3.58\%). Seven CE cases were recorded in the abdomen and three cases each in the gall bladder and in the kidney. Various other atypical localizations were identified, such as the acetabulum, brain, breast, cardiac, cervical, hard nodule, hepatogastric, left iliac fossa, neck, omentum, ovary, orbit, parietal, shoulder, and vertebrae. The majority of the patients had single organ involvement $(96.67 \%)$, while few had multiple organ involvement (3\%). Patients with multiple organ involvement included four cases: liver and omentum $(0.40 \%)$, liver and spleen $(0.80 \%)$, liver and lungs $(1.19 \%)$, and liver/spleen/pelvis $(0.80 \%)$. The diameter of the cysts most commonly measured was $\leq 4 \mathrm{~cm}(41.0 \%)$, followed by $7-8 \mathrm{~cm}$ $(17.5 \%)$ (Table 2). The reported CE cases and incidence per 100.000 during 2006-2021 are shown in Table 3. 
Table 2. Size-wise distribution of single and multiple cysts in human CE cases from Khyber Pakhtunkhwa province, Pakistan.

\begin{tabular}{ccccccc}
\hline \multirow{2}{*}{ Number } & \multirow{2}{*}{ Size (cm) } & \multicolumn{5}{c}{ Number of Cysts } \\
\cline { 3 - 7 } & & Single & Multiple & Multiple/Single & Not Available & Total \\
\hline 1 & $\leq 4$ & $10(9.7 \%)$ & $39(37.9 \%)$ & - & $54(52.4 \%)$ & $103(41.0 \%)$ \\
2 & $5-6$ & $10(24.3 \%)$ & $23(56.0 \%)$ & $1(2.4 \%)$ & $7(17.0 \%)$ & $41(16.3 \%)$ \\
3 & $7-8$ & $8(18.1 \%)$ & $28(63.6 \%)$ & - & $8(18.1 \%)$ & $44(17.5 \%)$ \\
4 & $9-10$ & $5(18.5 \%)$ & $16(59.2 \%)$ & - & $6(20.7 \%)$ & $27(10.7 \%)$ \\
5 & $11-12$ & $4(25 \%)$ & $10(62.5 \%)$ & - & $2(12.5 \%)$ & $16(6.37 \%)$ \\
6 & $13-14$ & $1(16.6 \%)$ & $4(66.6 \%)$ & - & $1(16.6 \%)$ & $6(2.39 \%)$ \\
7 & $15-16$ & - & $4(66.6 \%)$ & - & $2(33.3 \%)$ & $6(2.39 \%)$ \\
8 & $17-18$ & $1(50 \%)$ & $1(50 \%)$ & - & - & $2(0.79 \%)$ \\
9 & $19-20$ & $1(33.3 \%)$ & $2(66.6 \%)$ & - & - & $3(1.19 \%)$ \\
10 & $21-22$ & - & $1(50.0 \%)$ & - & $1(50.0 \%)$ & $2(0.79 \%)$ \\
11 & $\geq 23$ & - & $1(100.0 \%)$ & - & - & $1(0.39 \%)$ \\
\hline \multicolumn{7}{c}{}
\end{tabular}

Table 3. Number of hospital-recorded cystic echinococcosis cases and their incidence per 100,000 in Khyber Pakhtunkhwa province, Pakistan (2006-2021).

\begin{tabular}{cccc}
\hline Year & Number of Reported Cases & Total Population $^{*}$ & Incidence Per $\mathbf{1 0 0 , 0 0 0}^{\text {Non }}$ \\
\hline 2006 & 1 & $18,575,729^{\mathrm{a}}$ & 0.005 \\
2007 & 4 & $18,575,729^{\mathrm{a}}$ & 0.021 \\
2008 & 13 & $18,575,729^{\mathrm{a}}$ & 0.070 \\
2009 & 21 & $18,575,729^{\mathrm{a}}$ & 0.113 \\
2010 & 15 & $18,575,729^{\mathrm{a}}$ & 0.080 \\
2011 & 23 & $26,000,000^{\mathrm{a}}$ & 0.090 \\
2012 & 42 & $26,000,000^{\mathrm{a}}$ & 0.161 \\
2013 & 11 & $26,000,000^{\mathrm{a}}$ & 0.042 \\
2014 & 14 & $26,000,000^{\mathrm{a}}$ & 0.053 \\
2015 & 14 & $26,000,000^{\mathrm{a}}$ & 0.053 \\
2016 & 11 & $26,000,000^{\mathrm{a}}$ & 0.042 \\
2017 & 18 & $35,525,047^{\mathrm{b}}$ & 0.050 \\
2018 & 21 & $35,525,047^{\mathrm{b}}$ & 0.060 \\
2019 & 30 & $35,525,047^{\mathrm{b}}$ & 0.084 \\
2020 & 12 & $35,525,047^{\mathrm{b}}$ & 0.034 \\
\hline
\end{tabular}

${ }^{*}$ Khyber Pakhtunkhwa population estimated according to demographic surveys at province level ${ }^{\text {a }}$ conducted in 2001 (18.58 million people) and 2011 ( 26 million people) and by national census ${ }^{b}$ conducted in 2017 (35.52 million people).

\section{Discussion}

Cystic echinococcosis is an endemic zoonotic disease in many regions of the world, but improved hygiene and by-product management at slaughterhouses (in particular, the disposal of infected organs), better human clinical management, and the implementation of control programmes for CE may decrease Echinococcus spp. infections and their sequelae. In Pakistan, the health care system has improved to some extent and brought out many reforms in the last few years but still there are numerous weaknesses like poor administration and a lack of access to trained staff and health policy monitoring. In Pakistan, one of the leading causes of CE in animals is due to socio-cultural practices such as home slaughtering, feeding dogs with the organs of livestock, a lack of deworming of shepherd dogs, and the presence of stray dogs, which are common in Pakistan, favouring the active transmission of the parasite [14]. These conditions enhance the chance of contact, providing ideal conditions for helminthic infections [27]. In addition, there is a lack of information on the burden of CE in Pakistan, since many patients facing financial difficulties do not seek medical attention, and such cases remain undiagnosed and undetected [25].

In the current study, the highest rates of infection were reported in the RMI hospital compared to PMC, KTH, and IKD. The highest number of CE cases reported in RMI might 
be due to the fact that this centre also serves patients from neighbouring Afghanistan. In PMC, a higher number of CE cases was reported in $2019(n=15)$ followed by $2012(n=13)$, $2018(n=11), 2017(n=11), 2015(n=8), 2013(n=6), 2011(n=4), 2016(n=3)$, and 2014 $(n=3)$. In RMI, a higher number of cases was reported in the year $2012(n=29)$ followed by $2009(n=21), 2011(n=19), 2010(n=15), 2008(n=13), 2019(n=11), 2014(n=11), 2016$ $(n=7), 2015(n=6), 2018(n=5), 2013(n=5), 2007(n=4), 2020(n=3), 2021(n=1)$, and 2006 $(n=1)$. The current study showed also a higher frequency of CE cases in the 21-30 year age group followed by the 31-40 and 51-60 groups, respectively. These results are in line with other retrospective studies that showed a higher number of CE infections in the same age groups [25,28-31]. In the present study, the gender-wise investigation of CE cases revealed females with a high proportion of cases compared to males. These findings are similar to previous studies [26,30-33], where more females were infected than males, while they are in contrast with $[14,34]$, where more males were infected than females. The present study outcomes toward females may be biased by gender inequalities in Pakistan (social restrictions or a ban to visit hospitals). Moreover, a systematic review and meta-analysis of data has identified "being female" as a potential risk factor, although it is considered as a confounding factor, since some activities conducted by women in rural endemic areas could reflect a higher exposure to the parasite [35]. In fact, questionnaires administered during large cross-sectional study on CE conducted in Bulgaria, Romania, and Turkey did not find any statistically significant difference between gender prevalence [22,36].

For the last forty years, Pakistan has hosted more than 1.4 million Afghan immigrants, who have been forced to flee their homes because of the Soviet war in Afghanistan. Subsequently, the lack of basic facilities like shelter and employment in their home country are serious concerns making their return difficult. Currently, the majority of immigrants in Pakistan are of the Pushtun ethnic group, who live outside refugee camps [13]. The majority of CE cases reported in the present study were Afghan immigrants as documented by a report from hospitals in Khyber Pakhtunkhwa [14,37,38]. Moreover, these immigrants may also bring with them infected animals (e.g., dogs, livestock, and camels) into the country, especially in Khyber Pakhtunkhwa, which might have a major role in the transmission of CE in Pakistan [12,26].

Hospital data records from this study showed that in most of the cases, cysts were localized in the liver followed by the lungs. Similar observations were reported in Pakistan and worldwide [11,25]. Moreover, rare anatomical locations of the infection were also found in current study including, the pelvis, spleen, omentum, and ovary, as described by Khan and colleagues [39]. However, we reported atypical cases of CE infection of organs such as the acetabulum, neck, shoulder, and thyroid, which were not previously reported in the area. In the present analysis, the majority of positive CE cases were associated with single organ infection, which was in concordance with previous studies $[40,41]$. In this retrospective cohort, only few secondary $\mathrm{CE}$ infections were recorded. With a primary cyst rupture, released protoscoleces may form new cysts through secondary infection. However, if no cyst clinical history is present, it is difficult to find out whether multiple cysts are primary or secondary infections [25]. Most of the cases reported in the current study had a cyst size range $\leq 4 \mathrm{~cm}(41.0 \%)$ in diameter. Small cysts are usually asymptomatic or paucisymptomatic. When cysts exceed $5 \mathrm{~cm}$, they may complicate and become symptomatic; therefore, they can be more easily diagnosed.

\section{Materials and Methods}

Pakistan is divided into five provinces: Punjab, Sindh, Gilgit Baltistan, Baluchistan, and Khyber Pakhtunkhwa. Khyber Pakhtunkhwa is the third-largest province of Pakistan. Although KPK is the geographically smallest province, it has the third-largest economy and population. The north and the west of KPK province borders with Afghanistan, while the east and the northeast border with Azad Kashmir province (Pakistan), the northern areas with the Kashmir region (Pakistan-administered areas), the southeast with the Punjab state (India), and the southwest with the Baluchistan province of Pakistan. The capital city 
of KPK is Peshawar, which is the economic centre of the province with a $1257 \mathrm{~km}^{2}$ metro area and 1,964,102 million inhabitants [13]. The rural areas of KPK lack medical facilities; therefore, the population of rural areas visit mostly hospitals in the metropolitan area of Peshawar. Therefore, hospital data on human CE were collected from the major city of Khyber Pakhtunkhwa (KPK) province. All selected hospitals in this metropolitan area, such as Rehman Medical College (RMI), Peshawar Medical College (PMC), the Institute of Kidney Disease (IKD), and the Khyber Teaching Hospital (KTH) have also better diagnostic facilities compared to other hospitals and clinics located in rural areas. These hospitals also performed pathological investigation of echinococcal cyst samples received from the surrounding areas. The patient clinical data from 2006 to 2021 included in this study were postoperatively confirmed by histopathology. These four medical centres already had consent from the patients for sample characterization; so, after getting permission from the head of Pathology Departments, we had taken these samples from these hospitals. Age, gender, localization of cyst, size, and cyst number per organ (single or multiple) were recorded from medical reports for each surgically operated CE case. The frequency (\%) of human CE cases was calculated by using Microsoft Excel. Histopathologically confirmed cases were collected from the above-cited four major hospitals including RMI, PMC, IKD, and KTH (Figure 1), for which hospital management had already taken consent from each patient at the time of diagnosis/treatment. The samples from the hospitals were collected after getting permission from the head of the pathology department. The current study was approved by ethics committee of COMSATS University Islamabad under no. $\mathrm{CUI} / \mathrm{Bio} / \mathrm{ERB} / 2021 / 43$.

\section{Conclusions}

The current retrospective study revealed that CE is prevalent in KPK province of Pakistan, indicating CE as a significant public health problem in the study area. Although very limited studies have been conducted on Echinococcus/echinococcosis in Pakistan, the prevalence observed in the present study draws attention to $C E$ as a public health concern. Moreover, hospital records are mostly partial since registries are not structured, and they do not report all $\mathrm{CE}$ cases managed. The present study shows the emerging trend of echinococcosis among the Afghan immigrants in Pakistan, highlighting the transmission dynamics of the disease. Thus, the present report is a first step towards filling the knowledge gap of CE cases in KPK, Pakistan. Hence, more field-based studies are needed to collect clear epidemiological data on CE prevalence in Pakistan by means of population-based ultrasound surveys (cross-sectional studies).

Author Contributions: Conceptualization and study design by M.F.H. and H.A. Analysis and interpretation of data by H.K. and H.A. Writing the original draft preparation by M.F.H., H.A., M.S.A., A.C., M.A.N.S. and H.K. Statistical analysis by H.K. Supervision by H.A. and M.F.H. Writing, reviewing, and editing by H.A. and A.C. All authors have read and agreed to the published version of the manuscript.

Funding: This study was supported by the funding from the European Union's Horizon 2020 Research and Innovation programme under grant agreement number 773830: One Health European Joint Programme (MEME project; https:/ / onehealthejp.eu/jrp-meme/).

Institutional Review Board Statement: Ethical approval was obtained from the Departmental Ethics Review Board (ERB) at COMSATS University Islamabad (CUI), Pakistan (approval number: CUI/Bio/ERB/2021/43).

Informed Consent Statement: Not applicable.

Data Availability Statement: Not applicable.

Acknowledgments: The authors are thankful to the members of participating hospitals who helped us during the study.

Conflicts of Interest: The authors declare no conflict of interest. 


\section{References}

1. Casulli, A. New global targets for NTDs in the WHO roadmap 2021-2030. PLoS Negl. Trop. Dis. 2021, 5, 13-15. [CrossRef]

2. Craig, P.S.; McManus, D.P.; Lightowlers, M.W.; Chabalgoity, J.A.; Garcia, H.H.; Gavidia, C.M. Prevention and control of cystic echinococcosis. Lancet Inf. Dis. 2007, 7, 385-394. [CrossRef]

3. Budke, C.M.; Deplazes, P.; Torgerson, P.R. Global socioeconomic impact of cystic echinococcosis. Emerg. Infect. Dis. 2006, 12, 296-303. [CrossRef]

4. Agudelo Higuita, N.I.; Brunetti, E.; Mccloskey, C. Cystic echinococcosis. J. Clin. Microbiol. 2006, 54, 518-523. [CrossRef] [PubMed]

5. Basinger, S.C.; Khan, A.; Ahmed, H.; Afzal, M.S.; Simsek, S.; Budke, C.M. Estimation of the monetary burden of treated human cystic echinococcosis in Pakistan. Acta Trop. 2021, 222, 106026. [CrossRef] [PubMed]

6. Craig, P.S.; Rogan, M.T.; Campos Ponce, M. Echinococcosis: Disease, detection and transmission. Parasitology 2003, 127, S5-S20. [CrossRef]

7. Tamarozzi, F.; Deplazes, P.; Casulli, A. Reinventing the wheel of Echinococcus granulosus sensu lato transmission to humans. Trends Parasitol. 2020, 36, 427-434. [CrossRef] [PubMed]

8. Khan, H.; Zahoor, S.; Afza, M.S.; Khan, A.; Kaleem, I.; Shah, N.A.; Harandi, M.F.; Ahmed, H. Occurrence of massively enlarged multiple hydatid cysts in the lung and liver of a pediatric patient in Pakistan. Iran J. Parasitol. 2021, 16, 339-342. [CrossRef]

9. Alvarez Rojas, C.A.; Romig, T.; Lightowlers, M.W. Echinococcus granulosus sensu lato genotypes infecting humans-Review of current knowledge. Int. J. Parasitol. 2014, 44, 9-18. [CrossRef]

10. Ahmed, H.; Ali, S.; Afzal, M.S.; Khan, A.A.; Raza, H.; Shah, Z.H.; Simsek, S. Why more research needs to be done on echinococcosis in Pakistan. Infect. Dis. Poverty 2017, 6, 90. [CrossRef]

11. Khan, A.; Ahmed, H.; Khan, H.; Simsek, S.; Afzal, M.S.; Kilinic, S.G.; Kesik, H.K.; Yayi, G. A retrospective analysis on the cystic echinococcosis (CE) cases occurred in northeastern Punjab Province, Pakistan. Korean J. Parasitol. 2018, 56, 1-6. [CrossRef] [PubMed]

12. Khan, A.; Ahmed, H.; Khan, H.; Saleem, S.; Simsek, S.; Brunetti, E.; Afzal, M.; Manciulli, T.; Budke, C.M. Cystic echinococcosis in Pakistan: A review of reported cases, diagnosis, and management. Acta Trop. 2020, 212, 105709. [CrossRef] [PubMed]

13. Finance Division Government of Pakistan. Pakistan Economic Survey 2020-2021; Economic Adviser's Wing, Finance Division Government of Pakistan: Islamabad, Pakistan, 2021.

14. Khan, A.; Ahmed, H.; Simsek, S.; Gondal, M.A.; Afzal, M.S.; Irum, S.; Muhammad, I.; Mansur, H.; Fatima, A.; Ali, M.S.; et al. Poverty-associated emerging infection of cystic echinococcosis in population of Northern Pakistan: A hospital based study. Trop. Biomed. 2019, 36, 324-334.

15. Nur, A.; Abera, B.; Gunse, T. The significance (socio-economic impact) and control of Echinococcosis/Hydatidosis: A review. Eur. J. Biol. Sci. 2017, 9, 58-66.

16. Torgerson, P.R. The emergence of echinococcosis in central Asia. Parasitology 2013, 140, 1667-1673. [CrossRef] [PubMed]

17. Zhang, W.; Zhang, Z.; Wu, W.; Shi, B.; Li, J.; Zhou, X.; Wen, H.; McManus, D.P. Epidemiology and control of echinococcosis in central Asia, with particular reference to the People's Republic of China. Acta Trop. 2015, 141, 235-243. [CrossRef] [PubMed]

18. Borhani, M.; Fathi, S.; Darabi, E.; Jalousian, F.; Simsek, S.; Ahmed, H.; Kesik, H.K.; Hosseini, S.H.; Romig, T.; Harandi, M.F.; et al. Echinococcoses in Iran, Turkey, and Pakistan: Old diseases in the new millennium. Clin. Microbiol. Rev. 2021, 34, e0029020. [CrossRef]

19. Harandi, F.M.; Budke, C.M.; Rostami, S. The monetary burden of cystic echinococcosis in Iran. PLoS Negl. Trop. Dis. 2012, 6, e1915.

20. Altintas, N. Parasitic zoonotic disease in Turkey. Vet. Ital. 2008, 44, 633-646.

21. Gonlugur, U.; Ozcelik, S.; Gonlugur, T.E.; Arici, S.; Elagoz, S.; Cevit, R. The retrospective annual surgical incidence of cystic echinococcosis in Sivas, Turkey. Zoonoses Public Health 2009, 56, 209-214. [CrossRef]

22. Tamarozzi, F.; Akhan, O.; Cretu, C.M.; Vutova, K.; Akinci, D.; Chipeva, R.; Ciftci, T.; Constantin, C.M.; Fabiani, M.; Golemanov, B.; et al. Prevalence of abdominal cystic echinococcosis in rural Bulgaria, Romania, and Turkey: A cross-sectional, ultrasound-based, population study from the HERACLES project. Lancet Infect. Dis. 2018, 8, 769-778. [CrossRef]

23. Wang, L.Y.; Qin, M.; Liu, Z.; Wu, W.P.; Xao, N.; Zhou, X.N.; Manguin, S.; Gavotte, L.; Frutos, R. Prevalence and spatial distribution characteristic of human echinococcosis in China. PLoS Negl. Trop. Dis. 2021, 15, e0009996. [CrossRef]

24. Khan, A.; Ahmed, H.; Simsek, S.; Liu, H.; Yin, J.; Wang, Y.; Shen, Y.; Cao, J. Molecular characterization of human Echinococcus isolates and the first report of E. canadensis (G6/G7) and E. multilocularis from the Punjab Province of Pakistan using sequence analysis. BMC Infect. Dis. 2020, 20, 262. [CrossRef]

25. Muqaddas, H.; Arshad, M.; Ahmed, H.; Mehmood, N.; Khan, A.; Simsek, S. Retrospective study of cystic echinococcosis (CE) based on hospital record from five major metropolitan cities of Pakistan. Acta Parasitol. 2019, 64, 866-872. [CrossRef]

26. Khan, A.; Ahmed, H.; Khan, H.; Simsek, S.; Kilinc, S.G.; Kesik, H.K.; Yayi, G.; Celik, F.; Afzal, M.A. First report of Echinococcus canadensis (G6/G7) by sequence analysis from the Khyber Pakhtunkhwa province of Pakistan. Acta Trop. 2020, 209, 105559. [CrossRef]

27. Ali, S.A.; Akhtar, T.; Zaki, M.A.; Safi, W.A. Echinococcosis is an emerging public health problem in Pakistan. Int. J. Med. 2013, 3, 39-48.

28. Kebede, N.; Mitiku, A.; Tilahun, G. Retrospective survey of human hydatidosis in Bahir Dar, northwestern Ethiopia. East. Med. Health J. 2010, 16, 937-941. [CrossRef] 
29. Ghartimagar, D.; Ghosh, A.; Shrestha, M.K.; Talwar, O.P.; Sathian, B. A 14 years hospital based study on clinical and morphological spectrum of hydatid disease. J. Nepal Med. Assoc. 2013, 52, 349-353.

30. Abdul Hameed, M.F.; Habib, I.; Al-Azizz, S.A.; Robertson, I. A retrospective study of human cystic echinococcosis in Basrah province, Iraq. Acta Trop. 2017, 178, 130-133. [CrossRef]

31. Hajipirloo, H.M.; Bozorgomid, A.; Alinia, T.; Tappeh, K.H.; Mahmodlou, R. Human cystic echinococcosis in West Azerbaijan, Northwest Iran: A retrospective hospital-based survey from 2000 to 2009. Iran J. Parasitol. 2013, 8, 323-326. [PubMed]

32. Zhang, T.; Zhao, W.; Yang, D.; Piao, D.; Huang, S.; Mi, Y. Human cystic echinococcosis in Heilongjiang Province, China: A retrospective study. BMC Gastroenterol. 2015, 15, 29. [CrossRef] [PubMed]

33. Abebe, E.; Kassa, T.; Bekele, M.; Tsehay, A. Intra-abdominal hydatid cyst: Sociodemographic, clinical profiles, and outcomes of patients operated on at a tertiary hospital in Addis Ababa, Ethiopia. J. Parasitol. 2017, 2017, 4837234. [CrossRef]

34. Sharma, M.; Sehgal, R.; Fomda, B.A.; Malhotra, A.; Malla, N. Molecular characterization of Echinococcus granulosus cysts in north Indian patients: Identification of G1, G3, G5 and G6 genotypes. PLoS Negl. Trop. Dis. 2013, 7, e2262. [CrossRef] [PubMed]

35. Possenti, A.; Manzano-Román, R.; Sánchez-Ovejero, C.; Boufana, B.; La Torre, G.; Siles-Lucas, M.; Casulli, A. Potential risk factors associated with human cystic echinococcosis: Systematic review and meta-analysis. PLoS Negl. Trop. Dis. 2016, 10, e0005114. [CrossRef] [PubMed]

36. Tamarozzi, F.; Akhan, O.; Cretu, C.M.; Vutova, K.; Fabiani, M.; Orsten, S.; Pezzotti, P.; Popa, G.L.; Velev, V.; Siles-Lucas, M.; et al. Epidemiological factors associated with human cystic echinococcosis: A semi-structured questionnaire from a large populationbased ultrasound cross-sectional study in eastern Europe and Turkey. Parasit. Vectors 2019, 12, 371. [CrossRef]

37. Kern, S. The Infectious Disease Epidemiology Annual Report. 2017. Available online: https://www.gatestoneinstitute.org/1067 6/germany-migrants-Infectious (accessed on 12 July 2021).

38. Rasib, Q.; Khan, A.; Ahmed, H.; Nizamuddin, S.; Asif, F.; Afzal, M.S.; Simsek, S.; Khurshid, F.; Irum, S.; Hussain, N.; et al. Demographics of cystic echinococcosis patients treated surgically in Lahore, Pakistan: A single centre study from $2007-2018$. Helminthologia 2021, 58, 162-172. [CrossRef]

39. Khan, A.; Zahoor, S.; Ahmed, H.; Malik, U.; Butt, R.A.; Muzam, M.S.; Kilinc, S.G.; Noor, N.; Zahoor, S.; Afzal, M.S.; et al. A retrospective analysis on the cystic echinococcosis cases occured in Northeastern Punjab Province, Pakistan. Korean J. Parasitol. 2018, 56, 385-390. [CrossRef]

40. Ahmadi, N.A.; Badi, F. Human hydatidosis in Tehran, Iran: A retrospective epidemiological study of surgical cases between 1999 and 2009 at two university medical centers. Trop. Biomed. 2011, 28, 450-456.

41. Brundu, D.; Piseddu, T.; Stegel, G.; Masu, G.; Ledda, S.; Masala, G. Retrospective study of human cystic echinococcosis in Italy based on the analysis of hospital discharge records between 2001 and 2012. Acta Trop. 2014, 140, 91-96. [CrossRef] 